\title{
Erratum to: Erythrocyte Deformability and Oxidative Stress in Inflammatory Bowel Disease
}

\author{
Tulay Akman • Mesut Akarsu · Hale Akpinar •
}

Halil Resmi $\cdot$ Ebru Taylan

Published online: 4 December 2011

(C) Springer Science+Business Media, LLC 2011

\section{Erratum to: Dig Dis Sci}

DOI 10.1007/s10620-011-1882-9

Unfortunately one of the co-author's surname had been published as Sezer, it should be read as Taylan. The correct version is Ebru Taylan not Ebru Sezer.

The online version of the original article can be found under doi:10.1007/s10620-011-1882-9.

T. Akman ( $₫)$

Department of Internal Medicine, Faculty of Medicine,

Dokuz Eylul University, Izmir, Turkey

e-mail: tulaytuzel@gmail.com

M. Akarsu - H. Akpinar

Division of Gastroenterology, Faculty of Medicine,

Dokuz Eylul University, Izmir, Turkey

H. Resmi

Department of Biochemistry, Faculty of Medicine,

Dokuz Eylul University, Izmir, Turkey

E. Taylan

Research Laboratory, Faculty of Medicine,

Dokuz Eylul University, Izmir, Turkey 